\title{
An Investigation of Chinese Students' Acquisition of Oral and Written English through the Measurement of Processability Theory
}

\author{
Hao Tang (Corresponding author) \\ Foreign Language Department, Guangdong Institute of Science and Technology \\ No.513,Ke Hua Road,Tian He District, Guangzhou, 510640, P. R. China \\ E-mail: 519500016@qq.com \\ Yanyin Zhang \\ Chinese Studies, College of Asia and the Pacific, Australian National University \\ Acton ACT 2601, Australia \\ E-mail: yanyin.zhang@anu.edu.au
}

Received: 12-09-2014

Accepted: 10-11-2014

Published: 01-03-2015

doi:10.7575/aiac.ijalel.v.4n.2p.207

URL: http://dx.doi.org/10.7575/aiac.ijalel.v.4n.2p.207

\begin{abstract}
Processability Theory (PT) believes that L2 learner can not understand and produce those linguistic forms which are beyond the current stage of the language processor (Pienemann, 2007). Based on the understanding of the architecture of the language processor and how L2 is acquired under it, teachers can not only better predict the learners' L2 developmental stages, explain the learners' acquiring variations, but also indicate some constructive and objective guidelines for L2 teaching. So this study adopts the hierarchy of processing procedures applied to English (Pienemann, 1998) as the instrument to explore the two aspects of the English language acquisition. The final results support that Chinese college students' written English is better than their oral English. Besides, there is indeed a positive relationship between Chinese college students' written and oral English.
\end{abstract}

Keywords: Processability Theory, oral English, written English, emergency criteria

\section{Introduction}

Many studies about the difference between the oral and written English as L1 have been conducted since the beginning of the 20th century (Chafe \& Tannen, 1987). It is found that written English is more complicated than oral English in Grammar and lexical choices. But Blankenship (1962) also pointed out the opposite findings --- "little difference between the speeches and writings with respect to sentence length or complexity..." (as cited in Chafe \& Tannen, 1987, p. 385). Although these findings are heterogeneous and make it more sceptical to question the difference between the two aspects of English, the previous studies have accelerated and facilitated the study of English as L2. However, the research on the acquisition of both oral and written English as a foreign language is rather limited. So this study explored to what extent the learners' oral English acquisition was different from that of their written English; and are there any positive or negative relationships between the two aspects of language skills?

The writers here analyzed six Chinese junior college students' oral and written English using Pienemann's Processability Theory (PT), which asserts that the language learner can comprehend and produce the linguistic forms that the learners' current language acquisition stages can deal with.

\section{Theoretical Background}

\subsection{PT: the Architecture of the Processor}

In order to understand PT better and explain the rationale of the study, the understanding of the architecture of the processor is essential. With the assistance of this architecture, the language production course is explicated graphically on the foundation of logical and cognitive perceptions.

In terms of the processing architecture, there is a grammatical information shift within or among phrases of a sentence (Pienemann, 2006, p. 139). For example, in the sentence "Little Tom eats at school", "Little Tom" and "eats" show the grammatical information i.e. the third person singular. According to Levelt's Lexical-Functional Grammar (LFG), i.e. Levelt's model of language generation, the learners' language processor will examine whether "Little Tom" and "eats" are in accordance with each other regarding the third singular rule. In order to realizing that matching process, the learner has to obtain a phrase-building procedure first. So in the forementioned example, the noun phrase "little Tom" and the verb phrase "eats at school" have to be formed. Meanwhile, the two phrases have to be combined (ibid.). The learner has to form a procedure to combine the two parts together. The grammatical information "third person singular" should be contained in the procedure that produces the sentences where this information will be used. 
The rule applies to the information transfer within phrases as well. Take "three students" for example. The phrase consisting of the numeral "three" and the noun "students" holds the grammatical information "plural". When producing the phrase, the information in the two parts is compared during the noun phrase procedure, where the two phrases "three" and "students" are agreed.

In the following is a list of the processability hierarchy (Pienemann, 1998), which demonstrates the language acquisition sequence clearly:

1) Noun procedure (e.g., producing a simple word such as yes).

2) Category procedure (e.g., adding a past-tense morpheme to a verb)

3) Noun phrase procedure (e.g., matching plurality as in "two kids").

4) Verb phrase procedure (e.g., moving an adverb out of the verb phrase to the front of a sentence

"I went yesterday/yesterday I went.").

5) Sentence procedure (e.g., subject-verb agreement)

6) Subordinate clause procedure (e.g., use of subjunctive in subordinate clauses triggered

by information in a main clause).

\subsection{The Application of Processability Hierarchy}

PT believes that the processability hierarchy is implicationally ordered, which means each procedure is a must for the next procedure. So the language learners have to adhere to the hierarchy when they learn the target language.

When applied to English, the corresponding developmental stages for English morphology and syntax are clearly presented below (Pienemann, 2005, p. 24):

\begin{tabular}{|c|c|c|c|}
\hline Processing Procedure & L2 process & morphology & syntax \\
\hline 6 - subord. cl, procedure & main \& sub cl & & Cancel INV \\
\hline $5-$ S-procedure & inter-phr info & SV- agreement $(=3$ sg-s & Do2nd,Aux2nd \\
\hline 4 -VP-procedure & inter-phr info & tense agreement & $\mathrm{Y} / \mathrm{N}$ inv, copula inv \\
\hline 3 - phrasal procedure & phrasal info & $\mathrm{NP}$ agr, $\mathrm{Neg}+\mathrm{V}$ & ADV, Do-Front, Topi \\
\hline 2 - category procedure & lex morph & plural & canonical order \\
\hline 1 - word/lemma & $\begin{array}{l}\text { Possessive pro } \\
\text { 'words' }\end{array}$ & invariant forms & single constituent \\
\hline
\end{tabular}

Based on the understanding of the language learning process, language teachers can better conduct the teaching activities and learners will be more efficient than before to acquire the target language. Up to now, second language studies of language acquisition sequences have found a host of evidence for the universal sequences of second language learning (Wode 1976; Meisel, Clahsen, Pienemann 1981; Pienemann 1984, 1989, 1998; Pienemann, Keßler \& Roos, as cited in Lenzing, 2006, p. 223). This indicates that language learners acquire the language in a settled and anticipated order. Moreover, the stages of acquisition can not be skipped through formal education and instruction will be helpful if it focuses on structures from the 'next stage' (ibid.). This finding virtually paved a more scientific and efficient way for teachers to design their syllabuses.

In the context of PT, another valuable theory, Teachability Theory, was also proposed and supported by many researchers (Pienemann, 1984, 1987; Ellis 1989; Dyson 1996; Mansouri \& Duffy 2005; Keßler 2006, as cited in Lenzing, 2006, p. 223). The theory agrees that the learner can only acquire what he is ready to learn, and the learning is constrained psycholinguistically (Pienemann 1989, p. 52). The reasons why learners have to follow the anticipated paths and can not skip the universal sequences or stages of language acquisition are delineated by Pienemann (1998, p. 13) in the following:

because each stage requires processing procedures which are developed at the previous stage. 'Skipping stages' in formal instruction would imply that there would be a gap in the processing procedures needed for the learners' language. Since all processing procedures underlying a structure are required for the processing of the structure, the learner would simply be unable to produce the structure.

\section{Method}

\subsection{Participant Characteristics}

In order to find out the differences of Chinese students acquisition of oral and written English, the authors randomly chose two sets of students: three students who have passed College English Test Band 4 (CET 4) and another three students whose English levels were just between CET 4 and Practical English Test for Colleges (PRETCO) B. Generally speaking, we agree that students who have passed CET 4 are believed to be more advanced than students who only passed PRETCO B regarding their English levels. In terms of the official guidelines for university English teaching (Ministry of Education of the People's Republic of China, 2007), the CET takers must command around 4,500 English words plus 700 phrases, while the guidelines for junior college English teaching (Ministry of Education of the People's Republic of China, 2006), PRETCO B takers need just about 2,000 words. Apart from that, the students' reading speed required is also varied. If the student needs to meet CET 4 reading requirements, his reading rate must arrive at 70 
words per minute. As for PRETCO B attendants, 50 words per minute are the threshold. Nonetheless, what exact differences are there between the two groups and whether the advanced students' oral and written English levels are better than the intermediate-lower students' oral and written English levels are not distinctly disclosed, the acquisition in particular. Besides, whether there is a positive relation between the learners' oral and written English levels is also the study's concern.

With the assistance of the developmental stages depicted in PT, the above aims can be fulfilled. In the study, five oral English communicative activities and also five corresponding communicative written activities were designed to test the six subjects' specific morphosyntacitical knowledge, such as noun phrase agreement, tense agreement, subject-verb agreement, etc. (see Appendix A). Oral tasks included narrations, interviews and conversations. Parallel written tasks with similar topics were written narrations, picture descriptions, compositions and Chinese translations (Here, the similar topic would ensure that all the subjects were situated under the same external conditions and thus the validity of the study was secured). Meanwhile, in order to illicit the most natural language data, the six subjects did not know the contents and forms of the activities in advance. The oral and written activities designated to test the same linguistic items were conducted at different times to avoid the inter-activity influence on the results of the study. Oral and written activities were carried out on the same day.

\subsection{Research Design}

The five oral tasks and the five parallel written tasks were conducted separately at three times consecutively. Each time the subjects needed to finish two oral and another two written activities (except for the last time, there was only one task for both oral and written English). Every student was encouraged to speak for 6-8 minutes in each spoken English activity and then all the audio materials were transcribed. As for the written activity, all the subjects were required to finish each task in 20 minutes, except for the Chinese translation task which lasted for 30 minutes.

Another important element to consider was how to determine whether the subjects had started learning the focused linguistic knowledge. In other words, what's the acquisition criterion for the study? The determination of it has pivotal influence on the statistic data and the result of the study.

Due to the characteristics of language acquisition, the language research should focus on the development of the learning instead of the accuracy of the linguistic forms.

Logically, accuracy criteria are the first choice when considering the problem. However, Pallotti (2007, p. 362) noted that accuracy criteria had several flaws: First, the choosing of one criterion level over another was quite inconsistent. Some used 60 per cent, while others chose 90 per cent. Thus, the acquisition orders determined by the various accuracy criteria would result in different and confounding acquisition orders, though using the same data (ibid.); Second, with the high percentage of accuracy, the subjects demonstrated what they have exactly commanded regarding the related linguistic knowledge instead of when these linguistic forms started being integrated into their original linguistic knowledge repertoire (ibid.).

So the current study turned to emergence criteria, which was proposed to overcome the flaws brought about by accuracy criteria (Pallotti, 2007, p. 362). Meanwhile, at least one suppliance within the obligatory contexts was adopted as the emergence criteria in this study.

\section{Results}

After the activities were finished and data collected, the total number of the words of the first three oral tasks and also that of the written tasks were calculated (see Table 1 and Table 2).

Table 1. Total words of each task from the first three oral tasks (Note: the first three rows accidentally belong to the intermediate English proficiency group; the rest belong to lower-intermediate group)

\begin{tabular}{lllccc}
\hline No & Name & Task 1 & Task 2 & Task 3 & Sum \\
\hline 1 & Qiu & 786 & 470 & 902 & 2158 \\
\hline 2 & Yang & 384 & 247 & 598 & 1229 \\
\hline 3 & Fen & 307 & 339 & 502 & 1148 \\
\hline 4 & Liu & 431 & 276 & 423 & 1130 \\
\hline 5 & Wu & 140 & 186 & 325 & 651 \\
\hline 6 & Zhang & 214 & 112 & 247 & 573 \\
\hline
\end{tabular}

Table 2. Total number of words of each written task (Note: the same as above)

\begin{tabular}{llcccccc}
\hline No & Name & Task 1 & Task 2 & Task 3 & Task 4 & Task 5 & Sum \\
\hline 1 & Fen & 247 & 142 & 230 & 212 & 281 & 1112 \\
\hline 2 & Yang & 136 & 168 & 241 & 163 & 314 & 1022 \\
\hline 3 & Qiu & 155 & 191 & 194 & 149 & 312 & 1001 \\
\hline 4 & Liu & 116 & 151 & 200 & 129 & 296 & 892 \\
\hline 5 & Zhang & 134 & 160 & 145 & 162 & 211 & 812 \\
\hline 6 & Wu & 151 & 103 & 120 & 158 & 261 & 793 \\
\hline
\end{tabular}

Table 1 illustrates that though all of the six subjects were assigned the same three oral tasks i.e.: 
1) ask the informant to describe a day in the life of your mother or father;

2) ask the informant to talk about his activity yesterday;

3) and ask the students to describe what has happened led to the situation depicted in the picture. (see Appendix B, Penny Ur, 1988, pp. 106-109),

the number of words each of them uttered differed from each other, with Qiu, Yang and Fen producing 2158, 1229 and 1148 words respectively and Liu, Zhang and $\mathrm{Wu}$ uttered 1130, 651 and 573 words. The ranks of this list coincidently corresponded with those of written tasks for the same subjects, with Fen, Yang and Qiu achieving 1112, 1022 and 1001 words and Liu, Zhang and Wu's written tasks reached 892, 812 and 793 words. These results indicates that Qiu, Yang, Zhang who have passed CET 4 surpassed their counterparts who merely passed PRECTCO B in producing not only more oral utterances but also more written tokens.

Regarding Table 3, the suppliances of four morphological forms and their emergency rates were calculated.

Table 3. Comparison of the six learners' acquisition of oral and written English in Morphology

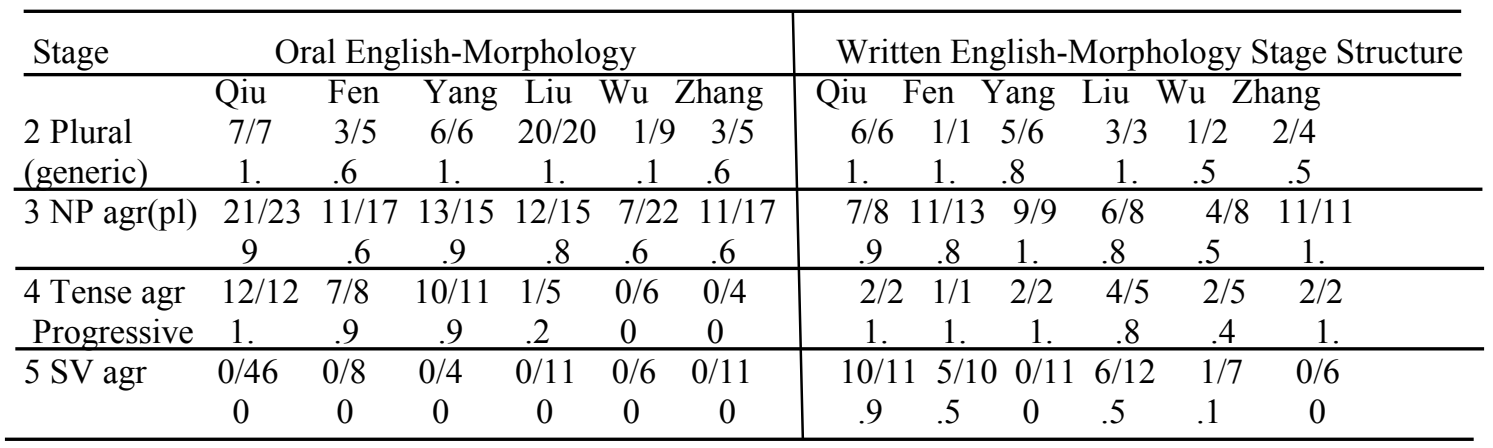

With a close look at the Table 3, we could see that Qiu and Fen's oral English reached Stage 4 (with emergency rates reaching 1. and .9 respectively) and their written English arrived at Stage 5 (with emergency rates reaching .9 and .5 respectively). Zhang reached at Stage 3 for his oral English (the emergency rate reaching .6) and her written English arrived at Stage 4 (the emergency rate being 1.). Liu's oral English arrived at Stage 4 and written English at Stage 5 (emergency rates reaching .2 and .5 respectively). As for Yang, both of her oral and written English levels were Stage 4 (emergency rates being .9 and 1. respectively). As for $\mathrm{Wu}$, his oral English reached Stage 3 (emergency rate arriving at .6) and written English Stage 5 (emergency rate reaching .1)

Regarding the tendency of the data in the table, it's evident that five of the six Chinese students written English levels were higher than their oral English levels. Moreover, the better their oral English was, the better their written English and vice versa (Yang is an exception; both her oral and written English reached Stage 4).

Studying Table 3 again, we could find that the linguistic forms like generic plural and tense agreement, present progressive tense in particular were not well acquired by subject $\mathrm{Wu}$. For example, during the 4th oral English activities, there were nine obligatory contexts for the linguistic form generic plural, but $\mathrm{Wu}$ provided only one correct suppliance, emergency rate .1, checking the following transcripts from Oral Task 4 (see Appendix C)

$\cdots$

9. Wu: The same. In my picture there are two house. One is big and one is small... Seagull, how many seagull, sea...(Seagull.) in your picture?

Zhang: No one.

10. Wu: Seagull... No one? My picture have four seagull.

Zhang: Do you have a moon in your picture?

34. Wu: Sea $\cdots$ seagull.

Zhang: I have no seagull.

35. Wu: Have no seagull. Anything different? Matter. A $\cdots$ maybe trees, trees, trees,

Zhang: I have four trees.

$\cdots$

In the above transcripts, the italicized seagull needed the suffix "s" to indicate generic category. However, there was only one supplicance "trees" among all the nine obligatory contexts.

Apart from that, all the six students performed awkwardly for the linguistic form the 3rd person singular. For example, among the 47 obligatory contexts of 3rd person singular, even Qiu, the most advanced student among the six students, did not provide a single suppliance, seeing the following transcripts (see Appendix D) 
30. After the dinner, he will also sometimes watch TV with us. Or sometimes

31. he will chat with other farmers outside of our home. Sometimes he also

32. will go to other place to talk with other people. And at about 9 o'clock, he

33. may will go to have a bath. Then he will come back, if he go out. After 10

34. o'clock, he always went to bed and prepare for the next day. That's

35. all.

In the above activity, Qiu was required to describe a day in his father or mother's daily life. Generally, the present tense was needed there to depict his father's routines daily. As a result, when the subject is "he", the suffix "s" is required to be added to the predicate denoting the third person singular. However, Qiu missed all the correct forms in this activity.

These problems happened to Noun Phrase agreement as well, According to Table 3, Wu's oral performance on NP agreement reached .6, which was much higher than his performance on generic plural .1. In addition, Zhang and Yang's written performance of Noun Phrases agreement (emergency rate being 1. and 1.) were also better than their counterparts of Generic Plural (emergency rate being .5 and .8). This was probably due to the fact that Chinese people do not use suffixes like $-\mathrm{s}$ or - es to refer to a generic category or class.

\section{Discussion \& Conclusion}

It is evident that the results of the study is in accordance with the study conducted by Zhu (2008), whose study concluded that there was a "positive and significant" relation between the subjects' oral and written English. In other words, the students who excelled at written English were good at oral English and vice versa. Besides, Zhu's study (2008) also found that the subject's written samples had more T-units and clauses than their oral samples, which meant that their written English was more syntacitically mature than their oral English. So it suggested that the L2 learners' written English was better than their oral English.

The present study using PT's processability hierarchy supported the above findings too. Moreover, it had more pedagogical significances, for it also pointed out the exact discrepancies between the subject's written and oral English. For example, Qiu's oral English stayed at Stage 4 (Tense Agreement), but her written English reached at Stage 5 (3rd Person Singular). If the teacher wants to improve Qiu's oral English, she/he ought to provide Qiu with more exercises focusing on Subject-Verb Agreement like 3rd Person Singular, which was the next stage Qiu was expected to reach.

Although the study disclosed clearly again the distinctions between oral and written English as a foreign language and indicated apparently the subjects' imbalance on commanding their English. It still had some defects. For one thing, the number of the subjects was rather small, which could be increased in the future study to ensure the validity of the findings. Another thing which needs to be aware of is the setting of emergency criteria. Due to the insufficient data produced by the subjects and the misunderstanding of some illicting questions, one suppliance within the obligatory contexts was employed as the emergency criteria. This should be avoided for one suppliance is not sufficient enough to prove that the subjects have acquired the designated linguistic forms.

Finally, though how to bridge the gap between the L2 learners' oral and written acquisition discrepancies is beyond the study, the prescription for this problem has enormous significance regarding the stagnant status quo of English teaching in China. Many scholars put forward some practical measures to address the problem. For instance, Yuan and Ellis (2003) and Ortega (1999) suggested that it should be better to raise the learner's attention to the form and meanwhile, allow them sufficient time while speaking in daily oral practice to ensure the accuracy first (as in Håkansson \& Norrby, 2007). Furthermore, speaking and writing are two totally different language producing modes and the generation of English, either oral or written English, must meet three essential factors i.e. knowledge of the language, focus on the form and planning time (Håkansson \& Norrby, 2007). But for oral English production, the three prerequisites are too rigorous when required at once.

As for the knowledge of the language and focus on the form, Spada and Lightbown (1999) put forward an effective and practical suggestion: explicit instruction on the contrastive metalinguistic information (between two languages). Long and Robinson (1998) also recommended explicit negative feedback in problem-solving tasks which would naturally divert the learner's "internal mental" attention to language itself and meanwhile, not distracting students' attention to the meaning of the activity as well.

\section{Acknowledgements}

I am very grateful to the students who took part in the study. Without them, the paper couldn't have been finished. Meanwhile, I must thank Dr Zhang Yanyin who not only worked with me to solve many problems while writing, but also greatly encouraged and motivated me to finish the paper. Finally, I want to thank my parents, who offered me wholehearted support whenever I need it. 


\section{References}

Chafe, W., \& Tannen, D. (1987). The relation between written and spoken language. Annual Review of Anthropology, 16 (1), 383-407. http://dx.doi.org/10.1146/annurev.anthro.16.1.383

Hakansson, G., \& Norrby, G. H. C. (2007). Processability theory applied to written and oral Swedish. In F. Mansouri (Ed.), Second Language Acquisition Research: Theory-Construction and Testing (pp. 81-94). United Kingdom: Cambridge Scholars Publishing.

Lenzing, A. (2008). Teachability and learnability: An analysis of primary school textbooks. In J. Keßler (Ed.), Processability Approaches to Second Language Development and Second Language Learning (pp.221-241). United Kingdom: Cambridge Scholars Publishing.

Long, M. H., \& Robinson, P. (1998). Focus on form: Theory, research, and practice. In C. Doughty \& J. Wlliams (Eds.), Focus on Form in Classroom Second Language Acquisition (pp.15-41). United Kingdom: Cambridge University Press.

Ministry of Education of the People's Republic of China. (2006). Guidelines for Junior College English Teaching. Beijing: Higher Education Press.

Ministry of Education of the People's Republic of China. (2007). University English Teaching Syllabus. Shanghai: Shanghai Foreign Language Press.

Ortega, L. (1999). Planning and focus on form in L2 oral performance. Studies in Second Language Acquisition, 21 (1), 109-148. http://dx.doi.org/10.1017/S0272263199001047

Pallotti, G. (2007). An operational definition of the emergence criterion. Applied Linguistics, 28 (3), $361-382$. http://dx.doi.org/10.1093/applin/amm018

Pienemann, M. (1984). Psychological constraints on the teachability of languages. Studies in Second Language Acquisition, 6 (02), 186-214.

Pienemann, M. (1989). Is language teachable? Psycholinguistic experiments and hypotheses. Applied Linguistics, 10 (1), 52-79. http://dx.doi.org/10.1017/S0272263100005015

Pienemann, M. (1998). Language processing and second language development: Processability theory, Amsterdam: John Benjamins Publishing Company.

Pienemann, M. (2005). Cross-linguistic aspects of processability theory, Amsterdam: John Benjamins Publishing Company.

Spada, N., \& Lightbown P. M. (1999). Instruction, first language influence, and developmental readiness in second language acquisition. The Modern Language Journal, 83 (1), 1-22. http://dx.doi.org/10.1111/0026-7902.00002

Ur, P. (1988). Grammar practice activities: a practical guide for teachers, United Kingdom:Cambridge University.

VanPatten, B., \& Williams, J. J. (2006). Theories in Second Language Acquisition: An Introduction, United Kingdom: Taylor \& Francis Group.

Yuan, F., \& Ellis R. (2003). The effects of pre-task planning and onLine planning on fluency, complexity and accuracy in L2 monologic oral production. Applied Linguistics, 24 (1), 1-27. http://dx.doi.org/10.1093/applin/24.1.1

Zhu, X. (2008). Is syntactic maturity a reliable measurement to investigate the relationship between English speaking and writing? The Asian EFL Journal, 10 (1), 133-153. 